\title{
Ordering policies for a dual sourcing supply chain with disruption risks
}

\author{
Jingjing Zhu, Shaochuan Fu \\ Beïing Jiaotong University (China) \\ zhjinging@163.com; fushaocbuan@,263.net
}

Received November 2012

Accepted March 2013

\section{Abstract:}

Purpose: The main purpose of this article is to explore the trade-off between ordering policies and disruption risks in a dual-sourcing network under specific (or not) service level constraints, assuming that both supply channels are susceptible to disruption risks.

Design/methodology/approach: Stochastic newsvendor models are presented under both the unconstrained and fill rate constraint cases. The models can be applicable for different types of disruptions related among others to the supply of raw materials, the production process, and the distribution system, as well as security breaches and natural disasters.

Findings: Through the model, we obtain some important managerial insights and evaluate the value of contingency strategies in managing uncertain supply chains.

Originality/value: This paper attempts to combine explicitly disruption management with risk aversion issues for a two-stage supply chain with two unreliable suppliers.

Keywords: ordering policies, disruption risks, two-stage supply chain, dual sourcing, risk aversion, stochastic model 


\section{Introduction}

As companies throughout all industries continue to globalize their operations and outsource significant portions of their value chain activities, they often end up relying heavily on order replenishments from distant suppliers (Patterson, 2007). The use of long-distance sourcing and the reliance on few key suppliers are exposing the procurement process to ever increasing disruption risks. Such trends have placed enormous pressures on supply chains. Organizations that cannot confront these challenges are facing tremendous difficulties in the new competitive environment.

Disruption risk includes: operational risks (equipment malfunctions, unforeseen discontinuities in supply, human centered issues from strikes to fraud), and risks arising from natural hazards, terrorism, and political instability (Kleindorfer \& Saad, 2005). Supply chain disruptions have been proven to have seriously negative impact on corporate profitability and shareholder value. Thus, it is essential for corporations to first analyze and understand these risks and then develop solutions to mitigate their impact. Risk management theory and practice provide alternative ways to hedge against specific disruption risks. One of the most common policies for risk mitigation is multiple-sourcing. Firms might use multiple-sourcing choice for a variety of strategic reasons, such as hedging against supply disruptions and safeguarding against predatory monopolistic practices (Burke, Carrillo \& Vakharia, 2007). In such cases, how to make the optimal ordering decision among two or more suppliers is worth studying.

In this paper, we focus mainly on the disruption risks of a dual sourcing supply chain. More specifically, generic newsvendor stochastic ordering models for risk-neutral and risk-averse decision-makers are proposed for a supply chain network of two unreliable competing suppliers and one retailer. The main objective is to capture the trade-off between ordering policies and disruption risks in a dual-sourcing network, assuming that both suppliers are susceptible to disruption risks. Finally, analytical solutions are obtained for the determination of the optimal expected total profit of the retailer. The consideration of two suppliers with different procurement prices and disruption probabilities, differentiates this work from the existing literature for dual-sourcing supply chains.

\section{Relevant literature}

The design and execution of appropriate approaches can play a critical role in handling risks and disruptions. Towards this direction, the literature dealing with the joint tackling of yield/inventory and risk management appears to be growing during the last decade.

Firstly we present the relevant quantitative effort in the single sourcing problem. Xia, Yang, Golany, Gilbert and Yu (2004) developed a deterministic EOQ-type inventory model for a two- 
stage supply chain with production-rate disruption risks. Yu and Zhao (2007) studied a random demand supply chain of a single supplier and a single retailer with different risk aversion and preference characteristics. They formulated and analyzed the optimal order quantities model, which revealed the impact of risk aversion and preference degree on optimal ordering quantity, price and supply chain coordination. Xiao and Qi (2008) investigated a one supplier-two competing retailers supply chain that experiences a disruption in cost and demand during a single period. Appropriate quantitative conditions are derived, which indicates when the maximum profit can be achieved once a disruption occurs. Moreover, Chahar and Taaffe (2009) formulated a stochastic programming model for the single sourcing case, in which the supplier is susceptible to risks of disruption.

Proceeding to the dual and multiple sourcing research papers, Tomlin and Wang (2005) developed a single period dual sourcing model with yield uncertainty, considering one reliable and one unreliable supplier, for the purpose of inventory and sourcing mitigation. In the same context, Tomlin (2006) developed a Markov chain model by considering capacity constraints for both suppliers and order quantity flexibility for the reliable vendor. Berger and Zeng (2005) developed a decision-tree model to determine the optimal size of a buying firm's supply base in the presence of risks. More recently, Wang and Gilland (2010) explored a model in which a firm can source from multiple suppliers or exert effort to improve supplier reliability. They characterize the optimal procurement quantities and improvement efforts and generate managerial insights. Schmitt and Snyder (2010) considered one case where a firm's only sourcing option is an unreliable supplier subject to disruptions and yield uncertainty, and a second case where a second, reliable (but more expensive) supplier is available. They develop models for both cases to determine the optimal order and reserve quantities. Although the literature covers several risk and yield management settings, in this paper, we attempt to bridge explicitly disruption management and risk aversion issues.

\section{Model Formulation}

\subsection{Main Assumption and Parameters}

Specifically, we consider a supply chain of one retailer and two competing, potentially unreliable suppliers which are both susceptible to supply chain disruptions, such as production, transportation- and security-related disruptions. We propose a single period inventory system where a single ordering decision is to be made before the sales period begins and emergency replenishment is not allowed. We denote with $\mathrm{p}_{\mathrm{j}}$ the probability of a supply chain disruption. Moreover, when a disruption occurs we assume that the supplier can provide nothing to the retailer. Different procurement prices, as well as disruption probabilities are considered for the supply sources. The objective is to maximize expected total profit. 
We first present the employed parameters. Demand $X$ is assumed to be a positive stochastic random variable with probability density function $f(x)$ and cumulative distribution function $F(x)$. The length of the selling period is $T$ time units. $c_{j}$ is the unit purchase cost paid to supplier $j(j=1,2)$. The unit selling price is denoted by $s$ and it is assumed that $s>c_{j}(j=1,2)$. The surplus stock that remains unsold at the end of the period can be sold to a secondary market at a unit salvage value $g$, it is assumed that $g<c_{j}(j=1,2)$. In addition, $b$ indicates the lost sales cost.

\subsection{Unconstrainted Model}

Initially, when none of the two supply channels faces a disruption (with probability $\left(1-\mathrm{p}_{1}\right)(1$ $\left.\mathrm{p}_{2}\right)$ ), the expected profit $\Pi_{0}\left(\mathrm{Q}_{1}, \mathrm{Q}_{2}\right)$ is obtained by the classical newsvendor problem analysis:

$$
\begin{aligned}
& \Pi_{0}\left(Q_{1}, Q_{2}\right)=\int_{0}^{Q 1+Q^{2}}\left[s x-c_{1} Q_{1}-c_{2} Q_{2}+g\left(Q_{1}+Q_{2}-x\right)\right] f(x) d x \\
& +\int_{Q_{1} Q_{2}}^{\infty}\left[s\left(Q_{1}+Q_{2}\right)-c_{1} Q_{1}-c_{2} Q_{2}-b\left(x-Q_{1}-Q_{2}\right)\right] f(x) d x
\end{aligned}
$$

When a disruption occurs only to the first supplier's channel (event that occurs with probability $\mathrm{p}_{1}\left(1-\mathrm{p}_{2}\right)$ ), a portion of $\mathrm{Q}_{2}$ initially ordered from supplier 2 can now be employed to satisfy demand. The expected profit $\Pi_{1}\left(Q_{1}, Q_{2}\right)$ is expressed by:

$$
\begin{gathered}
\Pi_{1}\left(Q_{1}, Q_{2}\right)=\int_{0}^{Q 2}\left[s x-c_{2} Q_{2}+g\left(Q_{2}-x\right)\right] f(x) d x \\
+\int_{Q_{2}}^{\infty}\left[s Q_{2}-c_{2} Q_{2}-b\left(x-Q_{2}\right)\right] f(x) d x
\end{gathered}
$$

Similarly, when a disruption occurs only to the second supplier's channel (event that occurs with probability $\left.\left(1-p_{1}\right) p_{2}\right)$, the expected profit $n_{2}\left(Q_{1}, Q_{2}\right)$ is expressed by:

$$
\begin{gathered}
\Pi_{2}\left(Q_{1}, Q_{2}\right)=\int_{0}^{Q 1}\left[s x-c_{1} Q_{1}+g\left(Q_{1}-x\right)\right] f(x) d x \\
+\int_{Q 1}^{\infty}\left[s Q_{1}-c_{1} Q_{1}-b\left(x-Q_{1}\right)\right] f(x) d x
\end{gathered}
$$

Moreover, when disruptions occur simultaneously to both suppliers (event that occurs with probability $\left.p_{1} p_{2}\right)$, there will be nothing to satisfy demand, and the expected profit $\Pi_{12}\left(Q_{1}, Q_{2}\right)$ is given by:

$$
\Pi_{12}\left(Q_{1}, Q_{2}\right)=-\int_{0}^{Q 1+Q 2} b x f(x) d x-\int_{Q 1+Q 2}^{\infty} b x f(x) d x
$$


Finally, the total weighted expected profit $n\left(Q_{1}, Q_{2}\right)$ is:

$$
\begin{gathered}
\Pi\left(Q_{1}, Q_{2}\right)=\left(1-p_{1}\right)\left(1-p_{2}\right) \Pi_{0}\left(Q_{1}, Q_{2}\right)+p_{1}\left(1-p_{2}\right) \Pi_{1}\left(Q_{1}, Q_{2}\right) \\
+\left(1-p_{1}\right) p_{2} \Pi_{2}\left(Q_{1}, Q_{2}\right)+p_{1} p_{2} \Pi_{12}\left(Q_{1}, Q_{2}\right)
\end{gathered}
$$

Therefore, the optimization model which represents the maximization of the total weighted expected profit $n\left(Q_{1}, Q_{2}\right)$, considering all possible combinations of disruption events on none, on one or on both supply chains, is:

$$
\begin{aligned}
& \text { (P): } \max \quad \Pi\left(Q_{1}, Q_{2}\right) \\
& \frac{\partial \pi(Q 1, Q 2)}{\partial Q 1}=\left(1-\mathrm{p}_{1}\right)\left\{\left(\mathrm{s}-\mathrm{c}_{1}+\mathrm{b}\right)-(\mathrm{s}-\mathrm{g}+\mathrm{b})\right)\left[\left(1-\mathrm{p}_{2}\right)\right. \\
& \left.\left.\int_{0}^{Q 1+Q 2} f(x) d x+\mathrm{p}_{2} \int_{0}^{Q 1} f(x) d x\right]\right\}=0 \\
& \frac{\partial \pi(Q 1, Q 2)}{\partial Q 2}=\left(1-\mathrm{p}_{2}\right)\left\{\left(\mathrm{s}-\mathrm{c}_{2}+\mathrm{b}\right)-(\mathrm{s}-\mathrm{g}+\mathrm{b})\right)\left[\left(1-\mathrm{p}_{1}\right)\right. \\
& \left.\left.\int_{0}^{Q 1+Q 2} f(x) d x+\mathrm{p}_{1} \int_{0}^{Q 2} f(x) d x\right]\right\}=0 \\
& H(x)=\left(\begin{array}{ll}
-(1-p 1)(s-g+b)[(1-p 2) & -(1-p 1)(1-p 2)(s-g+b) \\
f(Q 1+Q 2)+p 2 f(Q 1)] & f(Q 1+Q 2) \\
-(1-p 1)(1-p 2)(s-g+b) & -(1-p 2)(s-g+b)[(1-p 1) \\
f(Q 1+Q 2) & f(Q 1+Q 2)+p 1 f(Q 2)]
\end{array}\right)
\end{aligned}
$$

Through calculation, we can get the result of $\left|H_{1}\right|<=0$ and $\left|H_{2}\right|>0$. Since the first order determinant has a negative value, and the second order one is greater than zero, then Eq. (5) is proved to be negative definite and thus concave to the optimal order lot sizes resulting from Eqs. (6) and (7). That is to say, the maximum value of $\Pi\left(Q_{1}, Q_{2}\right)$ is attained for $Q_{1}$ * and $Q_{2} *$ (optimal order lot sizes), by solving the system of equations (9) and (10), which are the simplified forms of (6) and (7).

$$
\begin{aligned}
& \left(1-\mathrm{p}_{2}\right) \mathrm{F}\left(Q_{1}+Q_{2}\right)+\mathrm{p}_{2} \mathrm{~F}\left(Q_{1}\right)=\left(\mathrm{s}-\mathrm{c}_{1}+\mathrm{b}\right) /(\mathrm{s}-\mathrm{g}+\mathrm{b}) \\
& \left(1-\mathrm{p}_{1}\right) \mathrm{F}\left(Q_{1}+Q_{2}\right)+\mathrm{p}_{1} \mathrm{~F}\left(Q_{2}\right)=\left(\mathrm{s}-\mathrm{c}_{2}+\mathrm{b}\right) /(\mathrm{s}-\mathrm{g}+\mathrm{b})
\end{aligned}
$$

\subsection{Model with Fill Rate constraint}

The basic model $(P)$ presented in the previous subsection corresponds to risk neutral decisionmakers. Model $(P)$ can also be extended through the consideration of a fill rate constraint in order to take into account the risk aversion factor. Fill rate $r$ measures the proportion of the stochastic demand that is met from the delivered quantity of products. As motivated earlier, 
risk-averse decision makers would prefer more "conservative" policies that lead to larger order quantities by setting an appropriate service level constraint.

The resulting optimization model, which represents the maximization of the total weighted expected profit subject to a fill rate constraint is:

$$
(\operatorname{Pr}): \max \pi\left(Q_{1}, Q_{2}\right)
$$

Subject to:

$$
r>r_{0}
$$

With:

$$
\begin{gathered}
\mathrm{r}=1-\frac{\text { Expected number of stockout units }}{\text { Mean Demand }}=1-\frac{E(n(\mathrm{Q} 1, \mathrm{Q} 2))}{\mu} \\
\mathrm{E}\left(\mathrm{n}\left(Q_{1}, Q_{2}\right)\right)=\left(1-\mathrm{p}_{1}\right)\left(1-\mathrm{p}_{2}\right) \int_{Q 1+Q 2}^{\infty}\left(x-Q_{1}-Q_{2}\right) f(x) d x+\mathrm{p}_{1}\left(1-\mathrm{p}_{2}\right) \\
\int_{Q_{2}}^{\infty}\left(x-Q_{2}\right) f(x) d x+\left(1-\mathrm{p}_{1}\right) \mathrm{p}_{2} \int_{Q 1}^{\infty}\left(x-Q_{1}\right) f(x) d x+\mathrm{p}_{1} \mathrm{p}_{2} \int_{0}^{\infty} x f(x) d x
\end{gathered}
$$

The Lagrangian relaxation of problem $(\mathrm{Pr})$ is the following:

$$
\text { (LPr): } \max \mathrm{L}\left(Q_{1}, Q_{2}, \lambda\right)
$$

With:

$$
\begin{gathered}
\mathrm{L}\left(Q_{1}, Q_{2}, \lambda\right)=\Pi\left(Q_{1}, Q_{2}\right)-\lambda\left(r_{0}-r\right) \\
\Pi_{r}\left(Q_{1}, Q_{2}\right)=r_{0}-r
\end{gathered}
$$

Combining Eqs. (11), (12) and (13), the results of derivation for $\Pi_{\mathrm{r}}\left(Q_{1}, Q_{2}\right)$ are as follows:

$$
\begin{aligned}
& \frac{\partial \pi \mathrm{r}(\mathrm{Q} 1, \mathrm{Q} 2)}{\partial Q 1}=\frac{1}{\mu}\left[\left(1-\mathrm{p}_{1}\right)\left(1-\mathrm{p}_{2}\right) \mathrm{F}\left(Q_{1}+Q_{2}\right)+\left(1-\mathrm{p}_{1}\right) \mathrm{p}_{2} \mathrm{~F}\left(Q_{1}\right)\right]=0 \\
& \frac{\partial \pi \mathrm{r}(\mathrm{Q} 1, \mathrm{Q} 2)}{\partial Q 2}=\frac{1}{\mu}\left[\left(1-\mathrm{p}_{1}\right)\left(1-\mathrm{p}_{2}\right) \mathrm{F}\left(Q_{1}+Q_{2}\right)+\mathrm{p}_{1}\left(1-\mathrm{p}_{2}\right) \mathrm{F}\left(Q_{2}\right)\right]=0 \\
& \mathrm{H}(\mathrm{x})=\frac{1}{\mu}\left[\begin{array}{lc}
(1-\mathrm{p} 1)(1-\mathrm{p} 2) \mathrm{f}(\mathrm{Q} 1+\mathrm{Q} 2)+ & (1-\mathrm{p} 1)(1-\mathrm{p} 2) \mathrm{f}(\mathrm{Q} 1+\mathrm{Q} 2) \\
(1-\mathrm{p} 1) \mathrm{p} 2 \mathrm{f}(\mathrm{Q} 1)] & (1-\mathrm{p} 1)(1-\mathrm{p} 2) \mathrm{f}(\mathrm{Q} 1+\mathrm{Q} 2)+ \\
(1-\mathrm{p} 1)(1-\mathrm{p} 2) \mathrm{f}(\mathrm{Q} 1+\mathrm{Q} 2) & \mathrm{p} 1(1-\mathrm{p} 2) \mathrm{f}(\mathrm{Q} 2)]
\end{array}\right.
\end{aligned}
$$


The first order determinant $\left|H_{1}\right|>0$, and the second order one $\left|H_{2}\right|>0$, which gives the fact that $\Pi_{r}\left(Q_{1}, Q_{2}\right)$ function is convex, then $-\Pi_{r}$ function is concave. Due to the fact that the Lagrangian is equal to the sum of two concave functions, it is also a concave function and thus the solution of the first order conditions of the Lagrangian relaxation problem gives the global maximum value for problem ( $\mathrm{LPr}$ ) and subsequently to problem ( $\mathrm{Pr}$ ).

The global maximum value for problem (Pr) is attained for $\mathrm{Q}_{1}{ }^{*}$ and $\mathrm{Q}_{2} *$ (optimal order lot sizes) and $\lambda^{*}$ (optimal value of the Lagrangian multiplier), by solving the following system of equations:

$$
\begin{gathered}
\left(1-\mathrm{p}_{2}\right) \mathrm{F}\left(Q_{1}+Q_{2}\right)+\mathrm{p}_{2} \mathrm{~F}\left(Q_{1}\right)=\left(\mathrm{s}-\mathrm{c}_{1}+\mathrm{b}+\frac{\lambda}{\mu}\right) /\left(\mathrm{s}-\mathrm{g}+\mathrm{b}+\frac{\lambda}{\mu}\right) \\
\left(1-\mathrm{p}_{1}\right) \mathrm{F}\left(Q_{1}+Q_{2}\right)+\mathrm{p}_{1} \mathrm{~F}\left(Q_{2}\right)=\left(\mathrm{s}-\mathrm{c}_{2}+\mathrm{b}+\frac{\lambda}{\mu}\right) /\left(\mathrm{s}-\mathrm{g}+\mathrm{b}+\frac{\lambda}{\mu}\right) \\
1-\frac{1}{\mu}\left[\left(1-\mathrm{p}_{1}\right)\left(1-\mathrm{p}_{2}\right) \int_{Q_{1}+Q_{2}}^{\infty}\left(x-Q_{1}-Q_{2}\right) f(x) d x+\mathrm{p}_{1}\left(1-\mathrm{p}_{2}\right) \int_{Q 2}^{\infty}\left(x-Q_{2}\right) f(x) d x\right. \\
\left.+\left(1-\mathrm{p}_{1}\right) \mathrm{p}_{2} \int_{Q 1}^{\infty}\left(x-Q_{1}\right) f(x) d x+\mathrm{p}_{1} \mathrm{p}_{2} \int_{0}^{\infty} x f(x) d x\right]=\mathrm{r}_{0}
\end{gathered}
$$

\section{Numerical Analysis}

Considering the above analysis, it appears useful to explore the behavior of the proposed models for alternative sets of parameters for the unconstrained problem $(P)$. Two levels are considered for the values of the purchase costs $\left(c_{j}\right)$ and disruption probabilities $\left(p_{j}\right)$ for each supply channel.

We assume that the unit selling price is $s=45$, the unit purchase cost paid to supplier 1 is $\mathrm{c}_{1}=21$, to supplier 2 is $\mathrm{c}_{2}=24$, the salvage value of unsold products is $\mathrm{g}=10$, the shortage cost is $b=15$. Moreover, it has been assumed that the retail firm faces a demand with $a$ uniform distribution pattern; the maximum demand is equal to 1000 units, while the minimum demand is equal to 0 unit.

We first investigate how the value of $Q_{1} *, Q_{2} *$ and the total weighted expected profit is affected by simultaneous changes of the disruption probabilities $\left(p_{j}\right)$. Table 1 illustrates the effect of various combinations of $\mathrm{p}_{1}$ and $\mathrm{p}_{2}$ on the optimal ordering quantity and then total weighted expected profit. 


\begin{tabular}{|c|c|c|c|c|c|}
\hline \multicolumn{1}{|c|}{$\mathrm{p}_{1}$} & 0 & 0.05 & 0.1 & 0.15 & 0.2 \\
\hline $\begin{array}{c}\left.\mathrm{Q}_{1}^{*}, \mathrm{Q}_{2}^{*}, \mathrm{n}\right) \\
\mathrm{p}_{2}\end{array}$ & $(600,0,4200)$ & $(600,0,3615)$ & $(462,138,3092)$ & $(308,292,2862)$ & $(231,369,2746)$ \\
\hline 0 & $(600,0,4200)$ & $(600,0,3615)$ & $(509,95,3071)$ & $(384,228,2753)$ & $(308,308,2562)$ \\
\hline 0.05 & $(600,0,4200)$ & $(600,0,3615)$ & $(534,73,3060)$ & $(432,187,2684)$ & $(363,264,2430)$ \\
\hline 0.1 & $(600,0,4200)$ & $(600,0,3615)$ & $(550,59,3053)$ & $(466,158,2636)$ & $(404,231,2331)$ \\
\hline 0.15 & $(600,0,4200)$ & $(600,0,3615)$ & $(560,49,3048)$ & $(490,137,2601)$ & $(436,205,2254)$ \\
\hline 0.2 & & & & & \\
\hline
\end{tabular}

Table 1. Optimal ordering quantity and total weighted expected profit based on $\mathrm{p}_{1}$ and $\mathrm{p}_{2}$

It is observed that when the probabilities of a disruption on the first channel lower than $5 \%$, the retailer utilizes only supplier 1 . While as the probabilities increases, the optimal solution moves from a solution that mainly utilizes the first supply chain to a solution that mainly utilizes the second one. When the disruption probabilities of two suppliers are the same, it is obvious that ordering more form supplier 1 brings better result because of its lower purchase cost. In case of $\mathrm{p}_{1}=0.2$ and $\mathrm{p}_{2}=0.05$ both channels are equally attractive, that is to say the $15 \%$ lower risk of supplier 2 just make up for his 3 units higher cost under this risks combination. Similar findings are obtained when keeping constant all the parameters and altering only the purchase costs or the ordering quantities.

\begin{tabular}{|c|c|c|c|}
\hline$\frac{\left(\mathrm{Q}_{1} *, \mathrm{Q}_{2} *, \Pi\right)}{\mathrm{p}_{2}}$ & 0.1 & 0.15 & 0.2 \\
\hline 0 & $(462,138,3092)$ & $(308,292,2862)$ & $(231,369,2746)$ \\
\hline 0.05 & $(509,95,3071)$ & $(384,228,2753)$ & $(308,308,2562)$ \\
\hline 0.1 & $(534,73,3060)$ & $(432,187,2684)$ & $(363,264,2430)$ \\
\hline 0.15 & $(550,59,3053)$ & $(466,158,2636)$ & $(404,231,2331)$ \\
\hline & $(600,0,3030)$ & $(600,0,2445)$ & $(600,0,1860)$ \\
\hline
\end{tabular}

Table 2. contrast of decisions considering risks or not

Furthermore, this research can also explain why dual sourcing is better than single sourcing for risk mitigation. When the disruption probability of supplier1 is less than $5 \%$, the optimal ordering policy is purchasing 600 units only from the supplier 1 to obtain the highest expected profit. While once this probability rises to more than $5 \%$, the expected profit would be constantly reduced along with the increase of the disruption probability. At this time, the introduction of a lower risk auxiliary supplier is very necessary. From table 2, we can clearly see that when the main supplier exists higher disruption risk, allocating a part of order quantities to the auxiliary supplier is a good choice to enhance the expected profit. While the models formulated in this article exactly solve how to allocate order quantities between two uncertain suppliers to obtain highest expected profit.

\section{Summary and Conclusions}

An effective disruption management strategy that enhances supply chain resilience is a necessary component of a firm's overall hedging strategy. Firms that do not account for the 
risk of disruptions are susceptible to the risk of severe financial and market-share loss. In this article, we examined the trade-off between ordering policies and disruption risks for an unreliable dual sourcing supply network. Stochastic newsvendor models are presented under both the unconstrained and fill rate constraint cases. Analytical solutions were obtained, while through the relevant numerical investigation important managerial insights are also provided.

This paper considered only the profit of retailer and the objective was retailer's profit maximization. While in fact, suppliers also make decisions in consideration of their own benefit. Thus, further research can extend to the whole supply chain, exploring the best solution for both retailers and suppliers, finally the whole supply chain. Future research directions to this work could also include the extension of the proposed models for multiple types of products, for more than one disruptive event that can simultaneously appear, for more than two supply sources, and for supply chains of more tiers.

\section{References}

Berger, P.D., \& Zeng, A.Z. (2005). Single versus multiple sourcing in the presence of risks. Journal of the Operational Research Society, 7(3), 250-261.

Burke, G.J., Carrillo, J.E., \& Vakharia, A.J. (2007). Single versus multiple supplier sourcing strategies. European Journal of Operational Research, 182, 95-112. http://dx.doi.org/10.1016/j.ejor.2006.07.007

Chahar, K., \& Taaffe, K. (2009). Risk averse demand selection with all-or-nothing orders. Omega, 37, 996-1006. http://dx.doi.org/10.1016/j.omega.2008.11.004

Kleindorfer, P.R., \& Saad, G.H. (2005). Managing disruption risks in supply chains. Production and Operations Management Society, 14(1), 53-68. http://dx.doi.org/10.1111/j.19375956.2005.tb00009.x

Patterson, J.L. (2007). Supply base risk assessment and contingency planning in emerging markets. Electrical Insulation Conference and Electrical Manufacturing Expo, 10, 342-347.

Schmitt, A.J., \& Snyder, L.V. (2010). Infinite-horizon models for inventory control under yield uncertainty and disruptions. Computers \& Operations Research, 39, 850-862. http://dx.doi.org/10.1016/j.cor.2010.08.004

Tomlin, B. (2006). On the value of mitigation and contingency strategies for managing supply chain disruption risks. Management Science, 52, 639-657. http://dx.doi.org/10.1287/mnsc.1060.0515 
Tomlin, B., \& Wang, Y. (2005). On the value of mix flexibility and dual sourcing in unreliable newsvendor networks. Manufacturing \& Service Operations Management, 7, 37-57. http://dx.doi.org/10.1287/msom.1040.0063

Wang, Y.M., \& Gilland, W. (2010). Mitigating supply risk: Dual sourcing or process improvement? M\&SOM-Manufacturing \& Service Operations Management, 12(3), 489-510.

Xia, Y.S., Yang, M.H., Golany, B., Gilbert, SM., \& Yu, G. (2004). Real-time disruption management in a two-stage production and inventory system. IIE Transactions, 36, 111-125. http://dx.doi.org/10.1080/07408170490245379

Xiao, T.J., \& Qi, X.T. (2008). Price competition, cost and demand disruptions and coordination of a supply chain with one manufacturer and two competing retailers. The International Journal of Management Science, 36, 741-753.

Yu, C.Y., \& Zhao, X.N. (2007). Supply chain optimization and coordination model with risk aversion and preference. System Engineering, 25, 157.

Journal of Industrial Engineering and Management, 2013 (www.jiem.org)

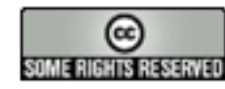

El artículo está con Reconocimiento-NoComercial 3.0 de Creative Commons. Puede copiarlo, distribuirlo y comunicarlo públicamente siempre que cite a su autor y a Intangible Capital. No lo utilice para fines comerciales. La licencia completa se puede consultar en http://creativecommons.org/licenses/by-nc/3.0/es/ 